\title{
NGS in diagnostics - where things can go wrong
}

\author{
Jordi Corominas Galbany ${ }^{1}$, Sanne Smeekens ${ }^{1}$, Marcel Nelen ${ }^{1}$, Helger Yntema ${ }^{1}$, Erik-Jan \\ Kamsteeg $^{1}$, Rolph Pfundt ${ }^{1}$, and Christian Gilissen ${ }^{1}$ \\ ${ }^{1}$ Radboud University Medical Center
}

August 2, 2021

\begin{abstract}
Massive parallel sequencing technology has become the predominant technique for genetic diagnostics and research. Many genetic laboratories have wrestled with the challenges of setting up genetic testing workflows based on a completely new technology. The learning curve we went through as a laboratory was accompanied by growing pains while we gained new knowledge and expertise. Here we discuss some important mistakes that have been made in our laboratory through ten years of clinical exome sequencing but that have given us important new insights on how to adapt our working methods. By providing these examples and the lessons that we learned from them, we hope that other laboratories do not need to make the same mistakes.
\end{abstract}

\section{Hosted file}

Clinical exome sequencing - where things can go wrong.docx available at https://authorea.com/ users/428677/articles/532484-ngs-in-diagnostics-where-things-can-go-wrong
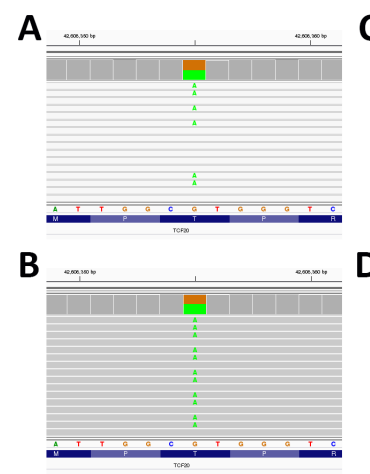

\section{G}
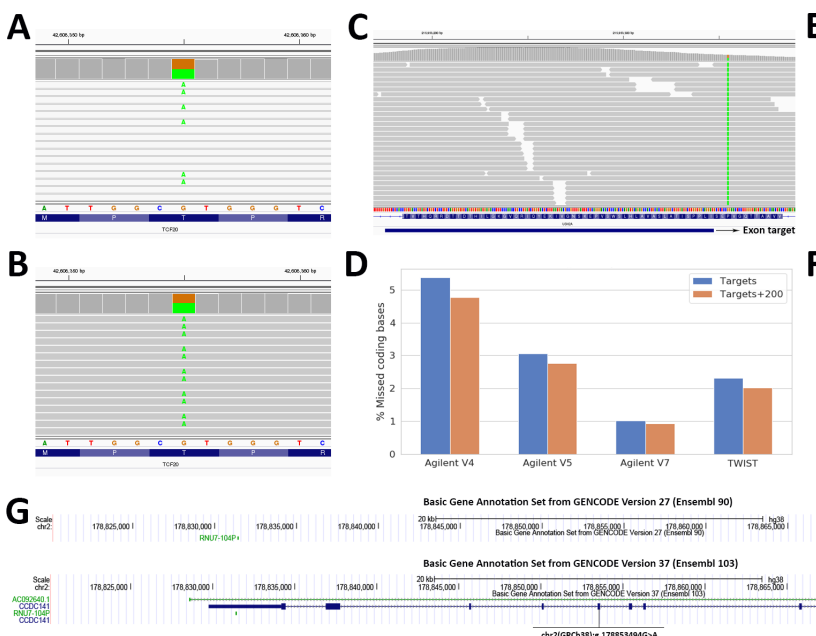

Basic Gene Annotation Set trom Gencoov Version 37 (Ensemb 103)
E

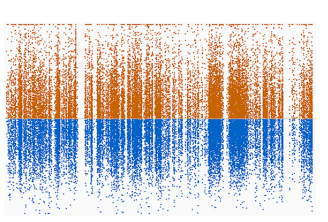

CNNS $=590 ; 5 D=1.36$

$\mathbf{F}$

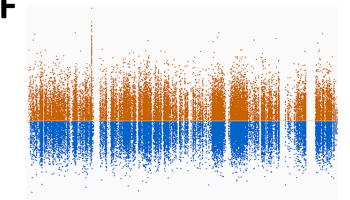

$\mathrm{CNNs}=9 ; \mathrm{SD}=0.49$
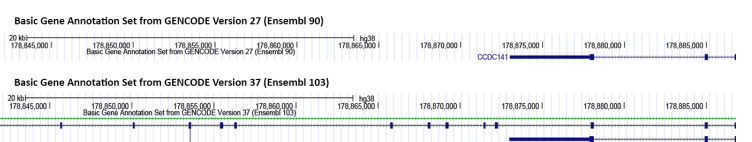

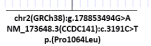




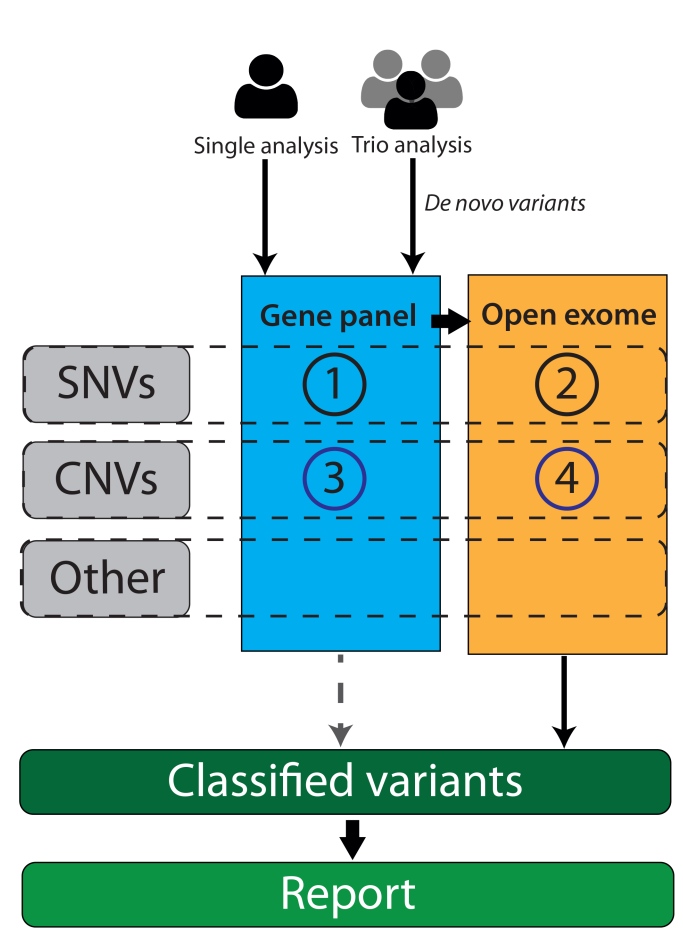

1 SNV Panel filtering Variants that are:

- Rare de novo

- Known pathogenic

- Rare coding/splice site

2 SNV Exome filtering Variants that are:

- Rare de novo

- Rare coding/splice site in

known genes

- Known pathogenic

- Rare truncating

- Unique coding/splice site

3) CNV Panel filtering

Variants that are:

- In other affected family

members

- Known pathogenic

- Rare and large CNVs

- In known associated disease genes

- In recessive disease genes

(4) CNV Exome filtering - As in (3) but genome-wide 


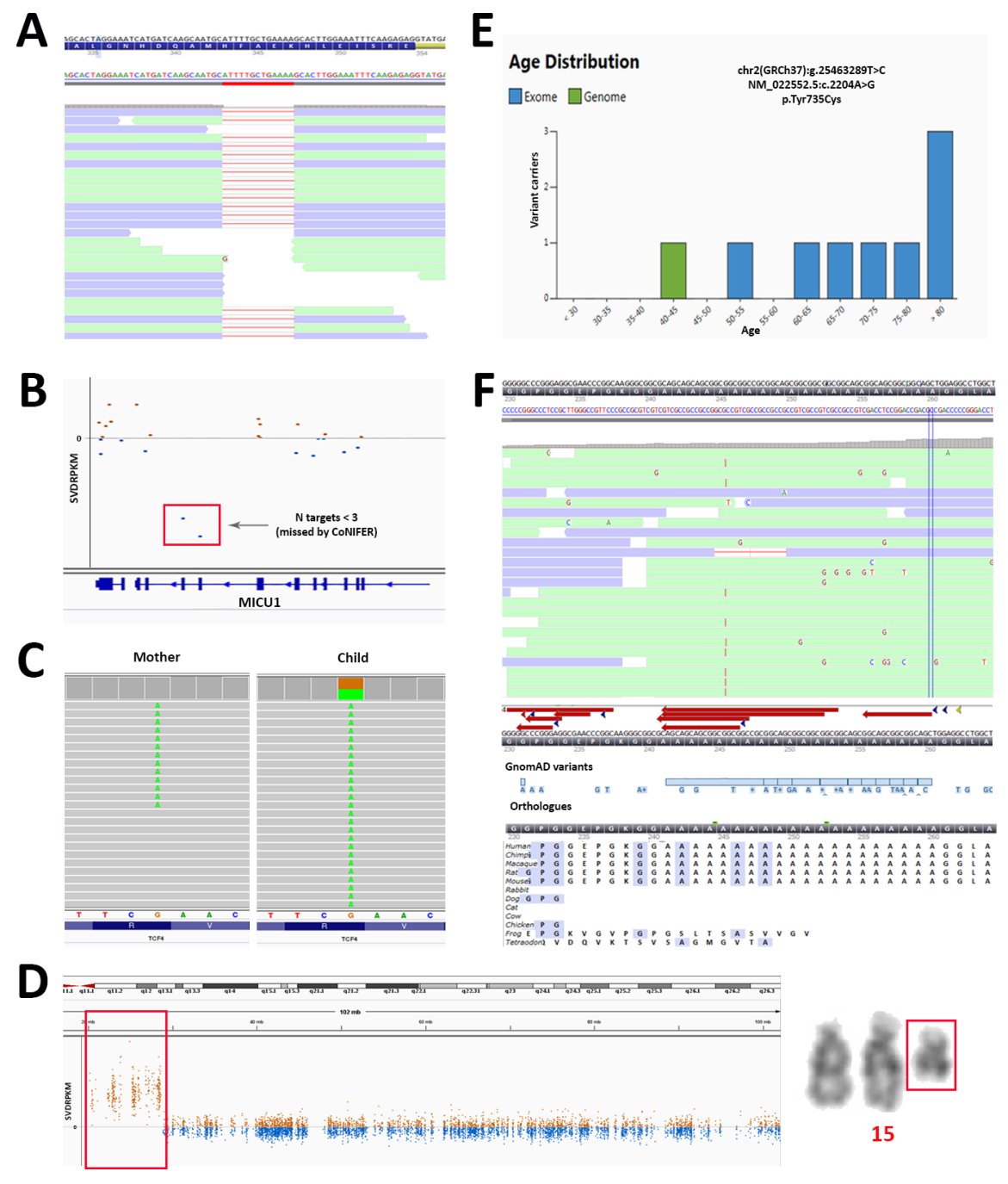

